\title{
The concept of a hybrid traction power supply system
}

\author{
Viktor Sychenko ${ }^{1, *}$, Valeriy Kuznetsov ${ }^{2}$, Yevheniy Kosarev ${ }^{1}$, Petro. Beh ${ }^{1}$, Yuriy Sayenko ${ }^{3}$, Bohdan Styslo $^{4}$, Mihail Pavlichenko ${ }^{5}$, Ihor \\ Vasilev ${ }^{6}$, and Mykola Pulin \\ ${ }^{1}$ DNURT, ${ }^{2}$ Railway Institute, ${ }^{3}$ PGTU, ${ }^{4}$ NTU "KhPI", ${ }^{5}$ LLC DDK, ${ }^{6}$ UrGUPS, ${ }^{7}$ Lviv Railway
}

\begin{abstract}
The growing shortage of energy resources to provide heavy traffic and high-speed traffic necessitates the development of a new power supply scheme for a traction network using sources of distributed generation of electric energy. Application of asymmetric distributed traction power system with the use of distributed generation allows to increase electric energy efficiency of the feed system of rolling stock, reduce its material capacity and increase the reliability of the functioning of the railway system as a whole. The proposed structure of the hybrid electric traction system involves the creation of a new paradigm aimed at ensuring high demands on the voltage and specific power in the traction network, which will allow to improve the quality and safety of the transportation process when increasing the energy performance indicators. This paradigm will allow to form a new philosophy of building traction power systems. The key elements of this philosophy are decentralization of generation and consumption of electric energy, the use of intelligent electric equipment, distributed power supply management in a single information space of the energy process during transportation. The peculiarity of the proposed work is the optimal combination of technological processes of transmission, consumption of electric energy and transportation, taking into account the specific conditions of functioning of the electrified section: points of connection of power sources and their type, profile of the track, schedule of trains, types of rolling stock and equipment. Conceptually, the hybrid traction power system is an electric hub, in which the inputs are generating points, and the output is the power supply system of the rolling stock. The internal structure of the electric power objects of the hub is determined by the type of transformation and accumulation of electric energy and ways of managing these objects in real time.
\end{abstract}

\section{Introduction}

Nowadays were formed two systems of traction power supply: direct and alternating current. Existing experience of their operation proves that the speed of up to $250 \mathrm{~km} / \mathrm{h}$ can be provided by existing systems of electric traction. It should be noted that the development and establishment of each of these systems was conditioned by the state of development of scientific and technological progress for a certain period of time [1]. The DC system from the moment of its appearance did not change structurally, but mainly changed the element base and used equipment. The $\mathrm{AC}$ system, on the contrary, from the very beginning of its application is constantly subject to various improvements. It can be stated that, not taking into account the declared advantages and prevailing on the implementation of the current system, the experience of its operation proves that, in general, the AC system no longer meets the requirements of the modern day. For all years of operation and modernization, the main drawbacks of this system were not eliminated: dangerous electromagnetic effects, asymmetric loading of phases and significant volumes of reactive energy transit [2]. Of course, scientific discussions about which electrification system is better, are conducted for a long time, but, as recent studies show, there is a gradual evolution of approaches from electrification of high-speed lines on alternating current up to the transition to a more thorough $24 \mathrm{kV} \mathrm{DC}$ system [3-5].

The methodological basis of this process is the development of modern power electronics, which allows implementation of the DC system with high voltage. Research of such systems is conducted long ago and it has already been proved that such systems in their technical and economic indicators far outweighed any advanced systems of AC electric traction [6]. Therefore, there are real prospects for the practical implementation of new DC systems taking into account the current state of power electronics. Getting high voltage in the contact network does not cause problems. For the rolling stock are known a number of possible variants of the converters structures. According to the authors, the ones that are currently used in power engineering for the twostage DC power supply with the intermediate link of the alternating current are most suitable. It's known the new development of the company $\mathrm{ABB}$ on arcless chamber switches. The company offers high-voltage IGBT for inverters with a switching frequency of about $2 \mathrm{kHz}$, which is enough for use in electric locomotives.

Among other things, today is a conceptually grounded approach to the creation of distributed power 
supply systems with high voltage and with the application of the principles of creating hybrid systems that use the following approaches: transmission of energy at high frequency, the use of amplitude-pulsewidth modulation and active filtering, the use of power cables with characteristics adapted for the transmission of electric energy by single-phase voltage of high frequency [7].

At the same time, it should be noted that the existing DC system owith voltage in the traction network $3 \mathrm{kV}$ is entitled to further application. Significantly strengthen traction power supply can not only the introduction of advanced technologies and modern equipment, but also the use of distributed power supply systems. The principles of constructing these systems were formulated by prof. Marquardt K. G. in the middle of the last century [8]. It is this ideology that should be entrusted to the development of new power supply systems and is already used in the construction AC systems $(2 \times 25 \mathrm{kV}$, $94 \mathrm{kV})$ and DC $(6 \mathrm{kV})$. When it is used, the power of the contact network is carried out by means of converters connecting to the longitudinal power line of the elevated voltage. The economic effect is achieved by reducing the section of wires of the contact network, reducing energy losses, maintaining the necessary voltage level in the contact network and increasing the utilization factor of the power of the main power equipment at the decrease of its installed capacity.

Modern trends in the development of the requirements of society impose high requirements on traction power devices that have to provide the required amount of transportation work throughout the year, taking into account the unevenness of the movement and the difference in the weight of trains. In connection with the rise in energy prices has emerged the need for the development of a new energy policy, modernization of the equipment of traction power supply systems and the search for untraditional traction power supply systems. Energy efficiency in modern conditions is the most important factor in the competitiveness of railways in the domestic and foreign markets of transport services.

It should be taken into account that the choice of technical solutions for the creation or reconstruction of a traction power supply system (TPSS) for the provision of high-speed and high-speed passenger traffic is based on the main parameters of the projected line, which include: maximum permissible and operating speed; type of electric rolling stock (ERS) and its characteristics; principles of organization of transportation and schedules of trains [9]. From the listed parameters significantly depends on the ability of the load of individual power devices and the system as a whole. The parameters of the TPSS and the power circuit of the contact network are selected in accordance with the accepted standards for the permissible load of the power equipment of the traction substations, the voltage on the current collectors vers of the ERS and the heating temperature of the traction network wires. It should be noted that there is a steady tendency to change the requirements for TPSS - not only providing normalized voltage, but also providing the necessary energy intensity of the traction network [10]. In this context, it should be noted that in existing TPSS, with excess aggregate capacity at traction substations, it is necessary to increase the traction network to provide the necessary energy indices and stability of the system as a whole. Paradoxically, the current state of traction power supply of direct current is characterized by a growing shortage of electric energy, which raises the problem of using independent power sources to supply power traction network points (PP).

To date, one of the main vectors for the development of modern electricity is the evolutionary transition from centralized generation of electric energy to distributed smart generation systems that use renewable energy sources. Their application increases the maneuverability of energy flows, which leads to an increase in the quality of electricity supply under uneven schedule of electricity consumption. The application of distributed generation and accumulation of electric energy can reduce the energy content of the power systems, increase its reliability and vitality through the backup energy stored in the storage devices [11]. There are already examples in the world of successful use of electricity from renewable sources in the electric traction system. For example, in 2011, the train traffic on the ParisAmsterdam route was unlocked using solar energy from photographic batteries installed on the train's route. Ukraine also implemented pilot projects for the parallel operation of the solar electric plants (SEP) and the external power supply system for power supply of $10 \mathrm{kV}$ on Sambir traction supply station and wind enerrgy plants (WEP) for supplying $35 \mathrm{kV}$ buses on the traction supply station StaryiSambir [12]. According to scientists, decentralization of electricity production is an important component of innovation and technological support for structural reform of the energy industry in order to increase its efficiency and, among other things, allows: to reduce electricity losses during transportation due to the maximum approximation of the source to the consumer, to reduce the number and length of main transmission lines, to reduce the consequences of accidents at central power plants and main transmission lines, to provide reciprocal multiple backup of power generating capacities.

The above stipulates the necessity of developing new approaches to the scheme of power supply of the traction network with the use of electric energy both from existing centralized power grids and from sources of distributed generation.

\section{It is known circuit design decisions of distributed traction power supply systems}

To date, there is no clear classification of distributed systems of traction power supply of direct current (DTPSS). It can be pointed out that three concepts of such systems have been formed $[13,14]$ :

- with increasing voltage in the traction network $(6,12$, $24 \mathrm{kV})$;

- with a voltage of $3 \mathrm{kV}$ in the traction network and AC power supply with an $\mathrm{AC}$ line $(10,35 \mathrm{kV})$; 
- with a voltage of $3 \mathrm{kV}$ in the traction network and the power supply of the direct current DC line $(6,12,24 \mathrm{kV})$.

An option for implementing such a system is presented in Fig. 1) [13].

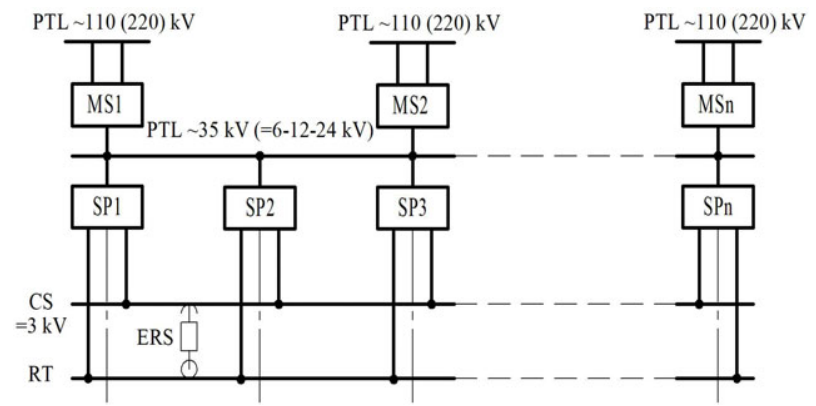

Fig. 1. Block diagram of distributed power system: MS - main substation, SP - supply point, RT - rail track; CS - catenary system; ERS - electric rolling stock.

Now in the Department of intellectual power supply systems in DNURT were formed two main approaches to circuit of DTPSS: system of distributed power with the use of alternative sources of electric energy (DTPSSA) [15] and a system of distributed power using single aggregate traction substations (DTPSSS) [16]. The implementation of the above-mentioned standards was carried out under the guidance of prof. Sychenko V.G. and Kuznetsov V.G. Options for the structural implementation of these systems are presented in Fig. 2 and 3 , respectively, and the power supply parameters are given in Table 1.

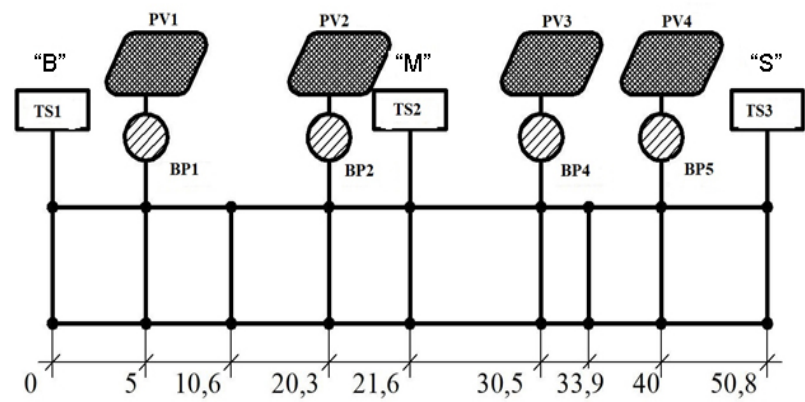

Fig. 2. Scheme of tested section of DTPSSA: TS - traction substation; BP - boost point; PV - photovoltaic power station.

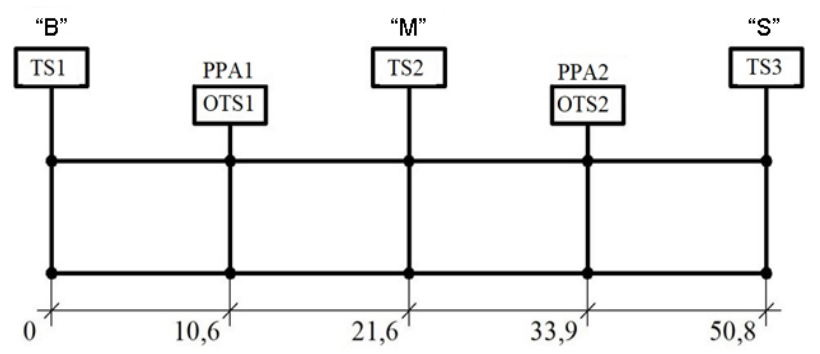

Fig. 3. Scheme of the section of DTPSSS with single-aggregate substations.

Each of these systems allows to provide the necessary requirements for the introduction of highspeed traffic and should be a priority direction for increasing the traction power supply of direct current in conducting the relevant feasibility study.
Table 1. Parameters of power supply systems.

\begin{tabular}{|c|c|c|c|c|c|c|c|}
\hline $\begin{array}{l}\text { Power, } \\
\text { MW }\end{array}$ & TS1 & \multicolumn{2}{|c|}{$\begin{array}{c}\text { OTS1 } \\
\text { (PPA1) }\end{array}$} & TS2 & \multicolumn{2}{|c|}{$\begin{array}{l}\text { (OTS2) } \\
\text { PPA2 }\end{array}$} & TS3 \\
\hline CTPSS & 12,6 & \multicolumn{2}{|c|}{ - } & 25,2 & \multicolumn{2}{|c|}{-} & 18,9 \\
\hline DTPSS & 10,4 & \multicolumn{2}{|c|}{5,2} & 10,4 & \multicolumn{2}{|c|}{5,2} & 10,4 \\
\hline PSSA & 12,6 & 6 & 2,5 & 12,6 & 2,5 & 6 & 12,6 \\
\hline $\begin{array}{c}\text { No-load } \\
\text { voltage, } \mathrm{V}\end{array}$ & \multicolumn{7}{|c|}{3500} \\
\hline
\end{tabular}

* Here CPSS - a centralized power supply system.

A comparative analysis of the energy performance of the proposed distributed systems and the existing centralized supply system is summarized in Table 2.

Table 2. Power indicators of traction power supply systems.

\begin{tabular}{|c|c|c|c|c|c|}
\hline \multicolumn{3}{|c|}{ Indicator } & CTPSS & DTPSS & PSSA \\
\hline \multirow{4}{*}{\multicolumn{2}{|c|}{$\begin{array}{l}\text { Mode of } \\
\text { voltage on the } \\
\text { current } \\
\text { collector of } \\
\text { ERS, V }\end{array}$}} & $\mathrm{M}(\mathrm{U})$ & 3130 & 3291 & 3397 \\
\hline & & $\max (\mathrm{U})$ & 3418 & 3500 & 3500 \\
\hline & & $\min (U)$ & 2643 & 2901 & 3255 \\
\hline & & $\begin{array}{l}\text { The value } \\
\text { of the } \\
\text { confidence } \\
\text { interval }\end{array}$ & 875 & 705 & 321 \\
\hline \multicolumn{3}{|c|}{$\begin{array}{l}\text { Electricity consumption for } \\
\text { traction, } \mathrm{kWh}\end{array}$} & 1495 & 1437 & $\begin{array}{c}944.8 \\
\text { (from } \\
\text { TS) } \\
+486.3 \\
\text { (from } \\
\text { the } \\
\text { PP) } \\
\end{array}$ \\
\hline \multirow{2}{*}{$\begin{array}{l}\text { Average } \\
\text { losses } \\
\text { power, } \\
\mathrm{kW}\end{array}$} & \multicolumn{2}{|c|}{$\begin{array}{l}\text { Excludinghigher } \\
\text { harmonics }\end{array}$} & 524 & 372 & 351 \\
\hline & \multicolumn{2}{|c|}{$\begin{array}{c}\text { Taking into } \\
\text { account the } \\
\text { higher harmonics }\end{array}$} & 631 & 428 & 409 \\
\hline \multirow{2}{*}{$\begin{array}{l}\text { Power } \\
\text { losses, } \\
\mathrm{kWh}\end{array}$} & \multicolumn{2}{|c|}{$\begin{array}{l}\text { Excludinghigher } \\
\text { harmonics }\end{array}$} & 174,9 & 123,9 & 113,6 \\
\hline & \multicolumn{2}{|c|}{$\begin{array}{c}\text { Taking into } \\
\text { account the } \\
\text { higher harmonics }\end{array}$} & 210,6 & 142,7 & 126,1 \\
\hline \multicolumn{3}{|r|}{$\cos \varphi$} & 0,77 & 0,79 & 0,81 \\
\hline \multicolumn{3}{|r|}{$\operatorname{tg} \varphi$} & 0,8 & 0,76 & 0,74 \\
\hline \multicolumn{3}{|c|}{ Efficiency } & 0,92 & 0,95 & 0,97 \\
\hline
\end{tabular}

\section{Hybrid system of traction power supply}

\subsection{Methodological principles of construction of hybrid TPSS}

The energy infrastructure of the existing TPSS has a fairly simple structure: external power supply lines, traction substations with lowering and cconverter transformers (units), from which the electric rolling stock and non-traction consumers receive power. In this TPSS, a rather simple circuit for the transformation and transmission of electric energy is used. At the same time, in existing TPSS there is virtually no means of regulating real-time power consumption modes, which at 
low utilization of aggregate power leads to additional losses of electric energy, and, accordingly, financial losses of electricity supply stations.

The rapid development of distributed generation based on non-traditional and renewable sources of energy, both at the level of power supply systems and directly to consumers, and their integration into centralized systems require the implementation of new principles for the construction of these systems and the creation of intelligent management systems for them with developed information and communication support. The unification of disparate systems of different levels into a single technological complex will ensure the implementation of new functional capabilities, the use of more advanced technologies in operation, and the creation of integrated centralized distributed systems with coordinated control of their modes and active participation of consumers in the electricity process $[17,18]$.

The current stage of development of world energy is characterized by a change in technological paradigm, which involves reducing the priority of centralized control. At the same time, the market of affordable modern technologies for the intellectualization of equipment, control systems and energy accounting, telecommunications and information security, small generation and others are developing. [17]. The technological basis of providing these processes is the use of Smart-grid platforms. All this creates the preconditions for the construction of integrated intelligent energy systems that have a multidimensional structure of functional features and developmental properties, combining multicomponent, intelligence, efficiency, reliability, manageability, flexible use of conversion technologies, transport, energy storage and active participation in these processes of the consumer. Implementation of the task requires the transition to a new structure of the traction power system using the principles of multi-agent management of available sources of electricity generation and consumption.

It should be noted that multi-resource power supply systems today are one of the main directions of energetic development. Their application allows to achieve synergistic effect as a result of the specific advantages of each of the individual power supply systems (electric, heat, gas, water supply, etc.) [19].

The key technological elements of the multi-resource power supply system are: sources of centralized power supply, electrical networks and installations, small energy objects, intelligent switching devices and energy storage devices. The application of the multi-electric system allows improving the whole complex of performance indicators of the electrical system, the main of which are: optimization of consumer load schedules, optimization of the modes of generating stations and network infrastructure, improving the quality of electric energy, and increasing the reliability of electricity supply. Proceeding from this, we can formulate a new philosophy of building an TPSS, which is based on the concept of an energy hub $[20,21]$. The peculiarity of the new philosophy is that the optimal set of technologies and devices for the electricity supply of a particular electrified area will be determined in each case separately, taking into account its properties, places of attachment of generation sources, profile of the track, schedule of trains, etc.

The power hub represents a model of a set of devices that implements the interaction between energy producers, transport infrastructure, on the one hand, and consumers - on the other hand. The main functions of the hub are the transfer, transformation and storage of energy resources. In a hub, power resources can be transmitted from input to output without changing the form (for example, electricity) or only with a significant change in quality (eg voltage transformation). In addition, energy resources can be transformed from one species to another, for example, a solar power plant converts solar radiation into electricity. The structure of the hub consists of four types of elements [20,21]:

1. Inputs - flows of electric power of various origin;

2. Converters (transformation, conversion);

3. Storage facilities (storage devices, accumulators);

4. Outputs - flows of electricity coming from the hub to consumers (electric rolling stock, non-traction consumers).

The block diagram of an electric hub is presented in Fig. 4.

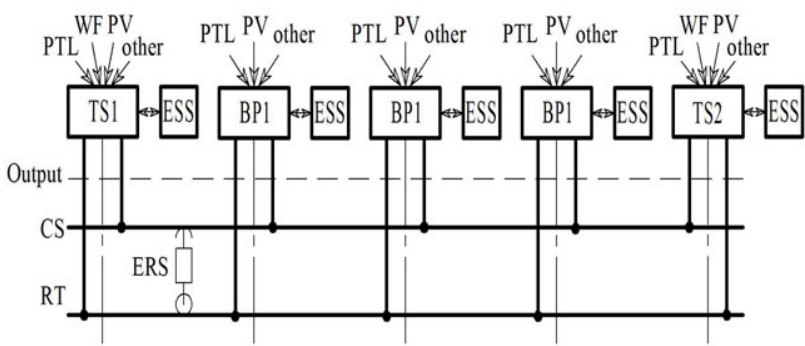

Fig. 4. Block diagram of an electric hub: TS - traction substation; BP - boost point; RT - rail track; CS - catenary system; ESS - energy storage system; PTL - power transmission line; WF - wind farm; PV - photovoltaic power station; ERS - electric rolling stock.

The proposed TPSS can be implemented with a high degree of intellectualization electricity accounting, distributed intelligent management of power consumption and intelligent forecasting. The peculiarity of this structure is the connection of wind power plants to traction substations, and the solar generation, both to traction substations, and for power supply of PP. This approach is caused by the circuitry of existing TPSS and is intended to minimize the material costs associated with replacement of equipment at the first stage of the implementation of the new system.

\subsection{Energy storage devices}

If earlier the electric storage devices (ESD) were considered as one of the means of energy saving, then with the development of eco-technologies, their application becomes a key task for the power industry. At present, the following main ESD are known: hydroaccumulating power plants, air-accumulating power stations, electrolytic capacitors, supercapacitors, electrochemical storage batteries, superconductive 
inductive energy storage units, fuel cells, hydrogen storage units, kinetic energy storage devices. In recent years, the greatest progress has been made in the development of hydrogen and kinetic ESD instead of earlier leading electrochemical storage devices [22].

The main areas of application of ESD in the electric power hub can be considered as:

- regulation of the load mode (alignment of day and night loading);

- regulation of the power flow of the consumer;

- providing more stable graphs of power output and loading schedule;

- increase of TPSS stability;

- improvement of the quality of electric energy with a sharp change in the traction load;

- reduction of the risk of systemic accidents.

Despite the wide range of electric energy storage devices, the specifics of their use in the energy sector imposes a rather serious constraint on the choice of a particular type, including energy, mass-size and economic indicators: energy intensity; service life; absence of "memory effect"; admissibility of fast charge modes; the ability to operate in the mode of large current overload; safety; low cost.An analysis of the characteristics of various types of electric power storage batteries [23] shows that each of the existing types of accumulators has advantages and disadvantages that should be taken into account when designing a system for the accumulation of electric energy in an electric power hub of TPSS.

According to experimental studies [24, 25], it is clear that the increase in the efficiency of the use of ESD can be achieved by expanding the frequency range of the efficient operation of the storage devices. For this purpose, it is expedient to include in the structure of the battery system different types of storage devices with different time characteristics of the charge-discharge cycle [26]. For example, although modern lithium battery batteries have sufficiently high frequency characteristics [24], their charging-discharging cycles are limited. In order to extend the lifespan of the amplifying point drives, it is expedient to allocate the reinforcement point tasks to two structurally coupled channels - low frequency (LFC) and high frequency (HFC). At fig. 5 shows a spectrograph of current consumed by an electric locomotive from a contact network, in which the intervals of frequencies are indicated $\Delta \mathrm{f} 1$ and $\Delta \mathrm{f} 2-$ respectively, the zone of action of the LFC and the HFC of the supply point.

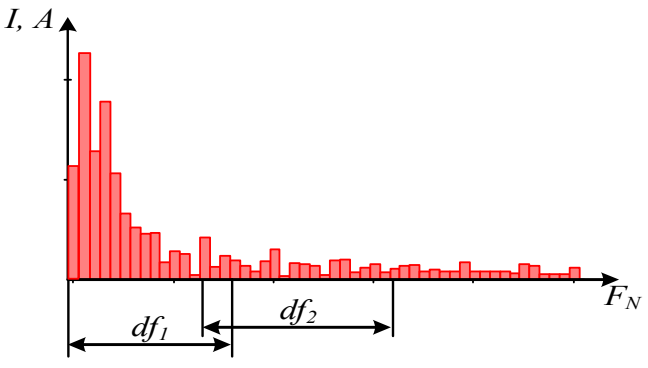

Fig. 5. To explain the zone of action of the LFC and the HFC of the power supply point.
The purpose of the LFC is to suppress all highfrequency current pulsation in the network. As an energy storage device in this channel it is expedient to use inertial flywheels in view of their high energy performance [27] compared with conventional electrolytic capacitors. As an energy storage device, the advantage of LFC should be givenLiFePO4 batteries that have improved power performance compared to traditional ones Li-Ion batteries [26]

To reconcile the energy characteristics of the ESD with the power supply (voltage level, charging level or discharge current) in the power supply point structure a matching converter is used. To effectively suppress pulsations in a wide frequency spectrum, it is advisable to carry out the APP according to the scheme of Fig. 6 . Available in the system of matching converters in the English literature are called "cooperative", they are characterized by the existence of a common system of control of several separate converters working on a joint load.

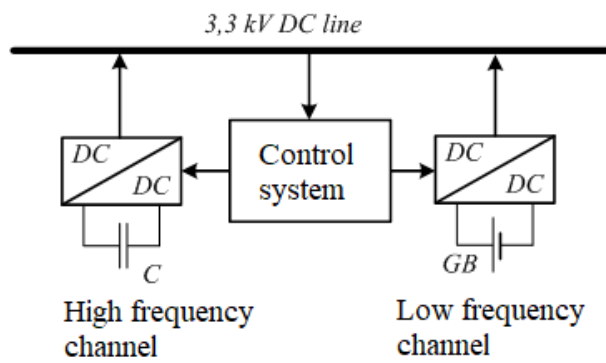

Fig. 6. The block diagram of a two-channel power supply point.

Since the boundaries of the typical charge / discharge time of the different types of drives vary in a sufficiently wide time range, frequency ranges $\Delta \mathrm{f} 1$ and $\Delta \mathrm{f} 2$ (Fig. 5) can be determined by superposition of energy and economic characteristics of storage devices of different types. Matching these storage devices should be done in real time, taking into account changes in load and generation (Fig. 7).

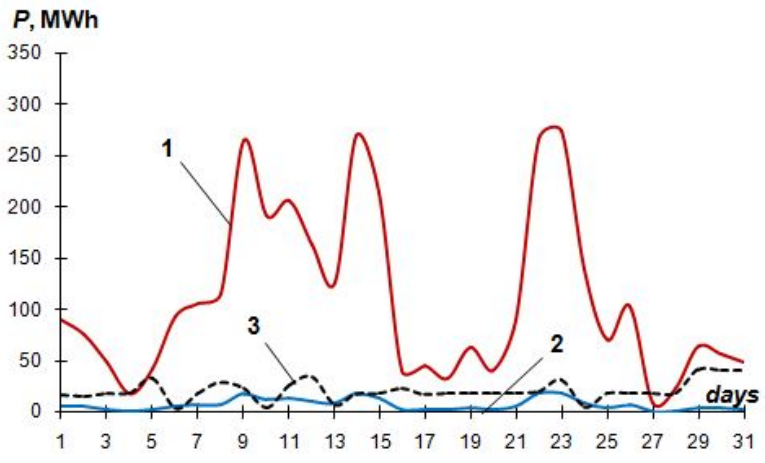

Fig. 7. Changes in load and generation: 1 - wind farm generation; 2 - photovoltaic generation; 3 - energy consumption.

In the development of algorithms for the functioning of intelligent devices in the hybrid TPSS it is necessary to take into account that the process of electricity consumption in the traction network occurs under the 
influence of heterogeneous perturbations: changes in the modes of operation of the electromotive force depending on the characteristics of the train timetable, the profile of the track and the available constraints, short-range separations of current collectors, the kind of transients, changes in the flows of generated energy, and so on. The mode of the voltage in the traction network under the influence of these perturbations has a non-stationary oscillatory nature with abrupt voltage changes that can lead to loss of voltage stability. As a result of the application of the quantitative approach to the calculation of the static stability of the traction power system, it was established that during the movement of the train in the real area there are zones of lack of voltage stability. The precise solution of the problem of stability evaluation is extremely complicated by the need to calculate nonlinear dependencies that determine the modes of operation of the traction power system and the electromotive composition [28]. The approach developed in [28] allows to calculate areas of stability of variant circuit designs of the traction network when introducing high-speed traffic and narrowing the range of voltage fluctuations. At the same time, it's not clear about the need for an asymmetric location of the PP, that means, depending on the specific conditions for ensuring voltage stability in the non-symmetric traction power system.

\subsection{Simulation results}

At fig. 8and, the block diagram of the BESD is presented, which includes a drive matching the DC / DC converter and charge controller. The DC / DC converter recharges or discharges the drive using the control strategy, according to the voltage in the contact network and the storage device charge (SoC). At fig. 8 b it's shown the equivalent diagram of battery modules, consisting of four elements [29].

a.

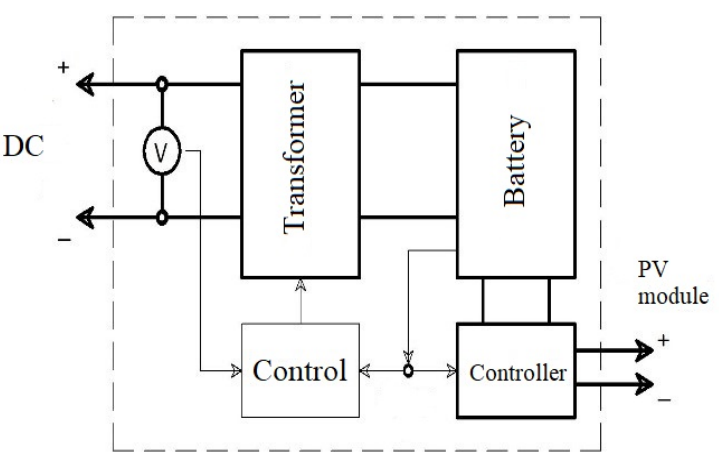

b.

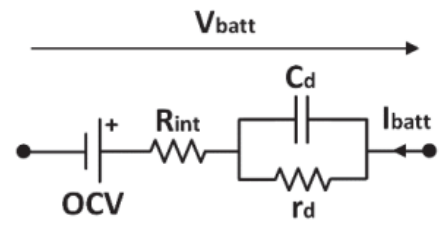

Fig. 8. Battery energy storage system: $a-$ structural scheme: $b$ - equivalent.
The ideal voltage source is the non-load voltage (OCV), which is influenced by the charge level of the storage device $(\mathrm{SoC})$; serial resistor Rvn represents the internal resistance of the storage device, while parallel $\mathrm{RC}$ link ( $\mathrm{rd}$ and $\mathrm{Cd}$ ) describes the transfer of charge and capacity respectively.

The electric model of the storage device can be described by Expressions $1-4$, where the first expression represents the Kirchoff equation for the substitution circuit (Fig. 1 b), the second - a polynomial $\mathrm{n}$ degree of the relationship between non-load voltage and the charge level of the storage device. The third equation models the law of varying the level of charge, in accordance with the magnitude of the charge current, and the fourth expression is a differential equation describing the work of a parallel RC link.

$$
\begin{aligned}
& U_{\mathrm{H}}(t+d t)=O C V(t)-R_{\mathrm{BH}} I_{\mathrm{H}}(t)-u_{d}(t+d t) \\
& O C V(S o C)=\alpha_{n} S o C^{n}+\alpha_{n-1} S o C^{n-1}+\ldots+\alpha_{0} \\
& S o C(t+d t)=S o C(t)+\frac{U_{\mathrm{H}}(t+d t) I_{\mathrm{H}}(t) d t}{3600 \cdot C_{\mathrm{H}}} \\
& u_{d}(t+d t)+r_{d} C_{d}\left(\frac{u_{d}(t+d t)-u_{d}(t)}{d t}\right)=\left\{\begin{array}{c}
r_{d} I_{\mathrm{H}}(t) \\
0
\end{array}\right.
\end{aligned}
$$

where, $u_{d}$ - the voltage of parallel RC link;

$d t$ - step sampling rate by time;

$\alpha_{n} \ldots \alpha_{0}$ - coefficients of interpolation;

$C_{\mathrm{H}}$ - capacity of the storage device.

Capacities of BESD for each PP are determined depending on the magnitude of the current of the amplifying current along the entire time of the passage of the ERS. By neglecting the amount of regeneration energy (assuming that energy was not supplied to the BESD, but only consumed throughout the entire range of motion), for discrete measurements of the current consumption, the capacity of the storage device is determined [30]:

$$
C_{\mathrm{H}}=\int_{0}^{T} \sum_{0}^{n-1}\left|i_{n}\right| d t
$$

where, $C$ - BESD capacity, A $\cdot \mathrm{h}$; $n$ - serial number of discrete measurement; $i$ - instantaneous value of the current consumption of the BESD, A;

Calculation of capacitance of storage devices of power points is realized on the example of the real electrified section of the Pridniprovskaya railway fig. 9.

The estimated section of the two-track, $128 \mathrm{~km}$ long, has 8 section between substations and receives power from 9 traction substations according to the given power schemes (Fig. 9). The non-load voltages and the internal resistances of the traction substations are determined based on their passport data. Traction network of the 
electrified area - M120+2MF100+ A185+ R65. Places for PP installation: $9 \mathrm{~km}, 33 \mathrm{~km}, 51 \mathrm{~km}, 66 \mathrm{~km}, 76 \mathrm{~km}$, $91 \mathrm{~km}, 109 \mathrm{~km}, 125 \mathrm{~km}$. The train schedule is shown at fig. 10 .

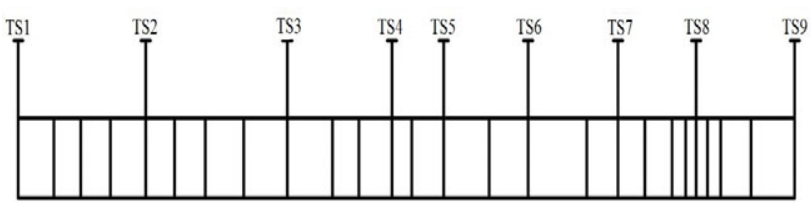

Fig. 9. Estimated section.

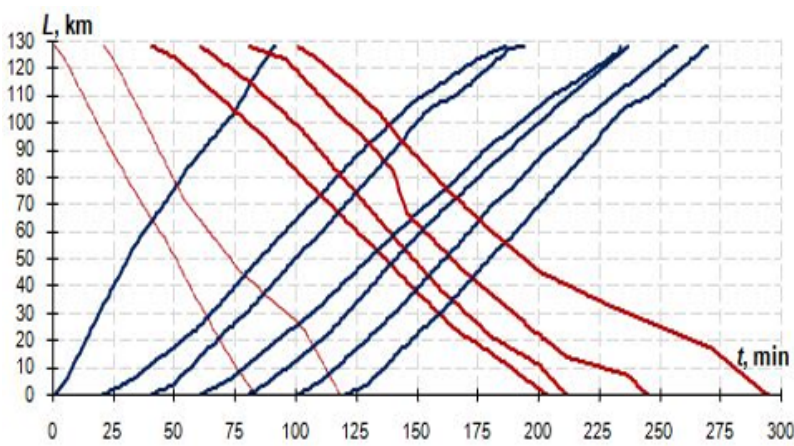

Fig. 10. Schedule of trains on section.

Based on the currents of amplification (Fig. 11) obtained as a result of the calculations carried out by means of a mathematical model, the capacities of the storage devices required for feeding the traction network and providing a predetermined level of voltage on current collectors of the ERS during the implementation of the train schedule are determined (Table. 3 ).

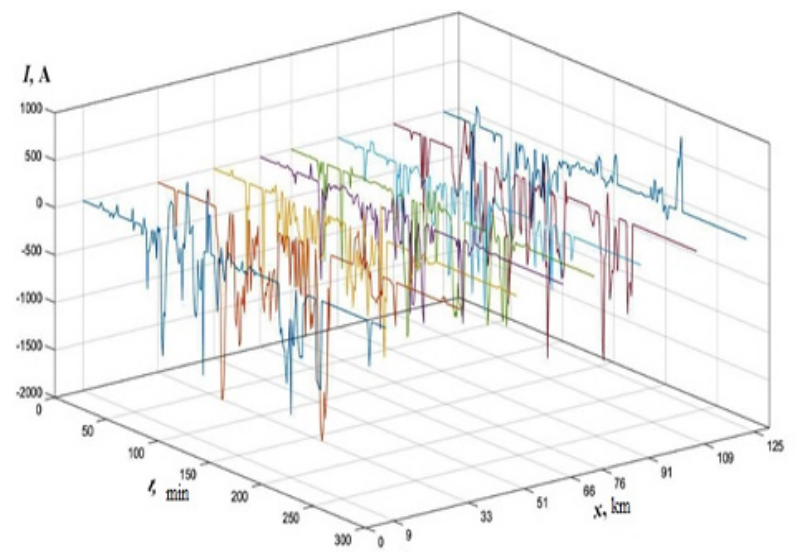

Fig. 11. Currents of BP.

Table 3. Capacities of the storage devices of BP.

\begin{tabular}{|c|c|c|c|c|c|c|c|c|}
\hline № & $\begin{array}{c}\text { BP } \\
1\end{array}$ & $\begin{array}{c}\text { BP } \\
2\end{array}$ & $\begin{array}{c}\text { BP } \\
3\end{array}$ & $\begin{array}{c}\text { BP } \\
4\end{array}$ & $\begin{array}{c}\text { BP } \\
5\end{array}$ & $\begin{array}{c}\text { BP } \\
6\end{array}$ & $\begin{array}{c}\text { BP } \\
7\end{array}$ & $\begin{array}{c}\text { BP } \\
8\end{array}$ \\
\hline $\begin{array}{c}\text { Capacit } \\
\text { y A. } h\end{array}$ & 705 & 1210 & 565 & 390 & 630 & 455 & 990 & 425 \\
\hline
\end{tabular}

\section{Conclusions}

1. The present state-of-the-art traction power supply systems with the introduction of high-speed traffic is due to the increasing requirements for voltage and power density, and, with increasing levels of traction load, the shortage of electric energy to meet these requirements.

2. The perspective direction of development of electric power systems is reduction of centralized supply of electric energy and centralized control of processes of its transfer and consumption with the use of Smarttechnologies.

3. With the spread of the ideology of multi-resource generation, it is necessary to form a new ideology of building traction power supply systems to improve the technical and economic indicators of its functioning.

4. The proposed circuitry of the modern traction power supply system in the form of an electric hub allows to use the available resources for generating electric energy and optimally combine the technology of its transmission and consumption, taking into account the specific conditions of the electrified section.

5. It is shown that the system of accumulation of electric energy in the proposed system of traction power supply should have two channels to compensate for lowfrequency and high-frequency oscillations of the load. The determination of the capacity of electric energy storage depends on the values of the consumed current, the nature of its change and the conditions for generating electric energy in the electric power hub of the traction power supply system.

\section{References}

1. V. G. Sychenko, El. supply of high-speed railways. Ukr. Railways. No. 5-6 (23-24), P. 32-39 (2015)

2. V. G. Sychenko, D. A. Bosiy, The quality of el. power use in el. traction syst. Modern techn. Syst. analysis. Simulation. № 48, P. 143-149 (2015)

3. B. A. Arzhanikov, A. T. Burkov, A. G. Galkin, V. A. Mansurov, I. O. Naboichenko, Persp. of the devel. of the el. traction syst. of $24 \mathrm{kV}$ high volt. for the Moscow-Yekaterinburg highway. No. 7, P. 4850 (2012)

4. V. V. Hananov, A. T. Burkov, D. V. Barch, Innovations and innovative proc. in traction power supply. Transport of the Russian Federation. No. 6, P. 34-39 (2012)

5. L. Abrahamsson, S. Ostlund, L. Soder, HVDC feeding with $O P F$ and unit commitment for el. railways. El. Syst. for Aircraft, Railway and Ship Propulsion (ESARS) (2012)

6. V. G. Sychenko, D. O. Bosiy, V. V. Bozhko, E. M. Kosarev, Yu. A. Borisovskaya, Ya. P. Shcherbak, B. O. Borshch, Comparative analysis of power supply syst. for high-speed highways. El. of transport. No. 10, P. 29-37 (2015)

7. P. V. Hubskyi, Power supply channels of distributed traction power supply syst. El. of transport. No. 15, P. 23-30 (2018)

8. K.G. Marquard, El. power supply of el. railways, 288 p. (1958) 
9. V. E Marskiy, Preparation of traction power supply for the org. of high-speed traffic on the St. Petersburg-Moscow line. P. 15-19 (2010)

10. A. T. Burkov, S. A. Burkov, M. A. Sharpilova, Modes of motion and features of traction calc. in determ. the loads on power supply systems of highspeed lines. El. innovative techn., high-speed and high-speed traffic on railway transport. Materials of the VI Intern. Symposium Oct. 25 - 28, 2011. - St. Petersburg: PGUPS, P. 337 - 349 (2013)

11. V. G. Sychenko, A. A. Matusevich, A. V. Rogoza, M. E. Pavlichenko, I. L. Vasiliev, N. N. Pulin, Enhancing en. efficiency in evolving power supply syst. Bulletin of the National Technical University "Kharkiv Polytechnic Institute". - Kharkiv: NTU "KhPI", No. 27 (1249), P. 182-186 (2017)

12. V. G. Sychenko, M. M. Pulin. Energy-efficient syst. Of DC traction power supply with distributed gener. Ukr. Railways, No. 5-6 (47-48), P. 28-32 (2017)

13. A. N. Marikin, A. V. Myzintsev New techn. in the constr. and reconstr. of traction subst. - Moscow: Marshrut, - 220 p. (2008)

14. B. A. Arzhannikov, I. O. Naboichenko, The concept of strengthening the syst. of traction power supply of a direct current of $3.0 \mathrm{kV}$ : a monograph, Yekaterinburg: UrGUPS (2015)

15. Ye. M. Kosarev, Improvement of the volt. mode in the traction power syst. of el. DC railways. Dissertation for the degree of candidate of techn. sc.. Dnipro, - 194 p. (2018)

16. P. V. Hubskyi Increase of en. efficiency of the syst. of traction power supply of direct current with high-speed motion. Dissertation for the degree of candidate of techn. sc. Dnipro, - 209 p. (2019)

17. N. I. Voropay, V. A. Stennikov, E. A. Barahtenko, Integrated en. syst. as an innov. dir. of en. future [Electronic resource]. Access mode: http://isem.irk.ru/energy21/papers/.pdf

18. A. V. Kirilenko, Intelligent El. Power Syst.: Elements and Modes: Generally. Institute of Electrodynamics of the National Academy of Sciences of Ukraine. - K.: IED NAN of Ukraine, 408 p. (2014)

19. A. V. Mohilenko, D. A. Pavlyuchenko, Multiresource syst. of power supply: a new paradigm, intelligent techn. solutions and technologies. Electro, No. 1. - P. 2-5 (2016)

20. M. Arnold, G. Andersson, Decomposed el. and natural gas, optimal power flow //16th Power
System Computation Conference, Glasgow, Scottland, UK, July 26-30, 7 p. (2008)

21. M. Geidl, G. Andersson, Optimal power flow of multiple en. carriers. IEEE Transactions is Power Systems. - Vol. 22. - No. 1 - P. 145-155 (2007)

22. V. Ya. Putilov, R. N. Shulga, Some techn. and environmental aspects of the use of power supplies in the en. sector. Electro, No. 1. - P. 6-11 (2016)

23. E. Sokol, V. Zamaruiev, S. Kryvosheev and oth., Specificity of el. en. storage unit application. IEEE First Ukraine Conference on El. and Computer Engineering (UKRCON). - Kyiv, - P. 432 - 435 (2017)

24. D. Cericola, PW Ruch, R. Ktz at al., Simul. of a supercapacitor / Li-ion battery hybrid for pulsed applications. Journal of Power Sources. - N9. - P. 2731-2736 (2010)

25. Pedram, Massoud, Naehyuck Ch. Et al, Hybrid el. en. storage syst. In Low-Power El. and Design (ISLPED) (2010)

26. B. O. Styslo, Peculiarities of the use of el. en. storage devices in the railroad's el. supply syst. Bulletin of the NTU "KhPI", Series: New solutions in modern technologies. - Kharkiv: NTU "KhPI". No. 9 (1285). - P. 76-82 (2018)

27. M. A. Sokolov, V. S.Tomasov, R. P. Jastrzebski, Sc. and techn. bulletin of inf. techn., mech. and optics. \# 4 (92). Comp. analysis of en. storage syst. Determination of optimal areas of app. of modern supermakhoviks. [Electronic resource]. Access mode:

https://cyberleninka.ru/article/v/sravnitelnyyanaliz-sistem-zapasaniya-energii-i-opredelenieoptimalnyh-oblastey-primeneniya-sovremennyhsupermahovikov (2014)

28. V. Sychenko, V. Kuznetsov, Ye. Kosariev, P. Hubskyi, V. Belozyorov, V. Zaytsev, M. Pulin, Devel. of the approach to ensuring the sustainability of the syst. of direct power supply syst. East European Journal of Adv. Techn. Iss. 5/2 (95), - P. 47-57 (2018)

29. L. W. Yao, J. A. Aziz, Modeling of a Lithium Ion Battery with Nonlinear Transmission Resistance, Applied Power Electronics Colloquium (IAPEC), IEEE, - P. 104 - 109 (2011)

30. V. V. Zamaruev, B. O. Styslo, Ye. M. Kosarev, Impr. the quality of el. en. in the syst. of power supply of rail transport by using el. en. storage devices. Bulletin of the National Technical University "KhPI", No. 27 (1249), - P. 360 - 364 (2017) 